\title{
1. Introduction to the Handbook on Cross-Cultural Marketing
}

Glen H. Brodowsky

\section{BACKGROUND}

A number of years ago, a very senior marketing professor who had served on many editorial review boards was speaking at a marketing educators' conference. He quipped, "Someday, I would like to write a paper entitled 'Doing Marketing in .' Identifying different marketing practices in other countries to learn how those countries compared to a home country was a new and popular approach at the time. However, it may be too limited to capture the nuances of marketing in today's interconnected global environment.

The second half of the twentieth century gave rise to global thinking in a more complex interconnected world. From America's post-war prosperity to the resurrection of the European economy through the Marshall Plan; from the emergence of multinational companies to the rise of Japan Inc. and other Asian Tigers; and from the growth of regional trading blocs from the North American Free Trade Agreement to the European Union, all indicators were that the world - along with consumer tastes - was converging (Levitt, 1983).

As the industrial twentieth century gave birth to the information-driven twenty-first century, the Soviet Union collapsed, and the end of the Cold War opened access to the markets and intellectual capital of the Eastern Bloc. China, the world's largest communist country, emerged as the world's factory and, recently, its second largest economy. This was matched by the breathtaking economic growth of the world's largest democracy, India. The twenty-first century was being hailed as the Pacific Century as global economic momentum seemed to have shifted from the West to Asia's emerging powerhouses.

Marketing researchers began to conduct cross-national, multinational, and cross-cultural (often used interchangeably) research to understand the opportunities and challenges of operating in this globally interdependent world. Cross-cultural studies began to compare consumers and employees from different countries along various dimensions such as Hall's work on time and proxemics and Hofstede's seminal five cultural dimensions. As units of analysis, countries provided convenient ways to segment markets and study differences between, say, United States (US) consumers compared with German consumers. There were many opportunities for "Doing Business in " papers comparing consumers in Country A with those in Country B. However, increased interaction among consumers worldwide 
resulting from advances in communication and transportation led to the emergence of global market segments not cleanly defined by the lines on a map.

Not everyone benefited from, nor shared enthusiasm for the new research and business opportunities the new global world order presented. Less than two decades into the twenty-first century, large swaths of the European and North American populations have soured on globalization. In 2016 - less than 25 years after its birth - the majority of voters in the United Kingdom voted to leave the European Union. Anti-European Union and anti-immigrant political parties gained ground in France, Germany, Italy, and other European Union countries. A populist candidate rode a wave of anti-globalization, anti-immigration sentiment all the way to the White House in the US.

Disillusionment with globalization, along with a rise in nationalist sentiment, may lead one to ask whether cross-cultural or international research will be necessary in the coming years and, if it is, what form it will take. One thing remains clear: cross-cultural marketing is a broad topic in today's technological, always-connected world.

While all international marketing is cross-cultural, not all cross-cultural marketing is international. Cultures are defined as groups of people who share a common language, set of norms, institutions, beliefs, and values. There are many ways such groups can be defined - only one of which is country. Other examples include world regions, trading blocs, regions within a country, or even generations. Each of these cultural or sub-cultural groups may represent a different market segment making cross-cultural marketing a challenging yet timely topic.

\section{WHY THIS HANDBOOK?}

Against the backdrop of these changes, Edward Elgar Publishing first invited me to serve as an editor for this volume on cross-cultural marketing research in 2018. From the beginning, I was very clear that I would only take on the challenge if the book encompassed both international as well as intra-national cross-cultural marketing research. Fortunately, the editor was very receptive to the idea of a volume that would build upon twentieth-century theories of international cross-cultural research to guide researchers in investigating the exciting challenges of twenty-first-century realities. I was also determined to put together a handbook that experienced as well as new researchers would find useful for helping them identify new research questions while equipping them with a strong grounding in the extant literature and methodological rigor.

Once I accepted this project, I recognized my biggest challenge was to convince some of the greatest thought leaders in the field to contribute to this endeavor. It was clear that not only could I not write the book myself, but also that I would need to find a co-editor who had more experience working with these leading researchers. I immediately contacted my colleague and friend, Camille Schuster, and invited (okay, begged) her to join me as co-editor. Camille has decades of experience not 
only as an academic researcher, but also as a consultant. Camille and Michael Copeland have co-authored two books in which they develop a cross-cultural classification model that puts cultures on a continuum between task orientation and relationship orientation. This is a model that is used by many researchers alongside other well-known cultural classification models including the Hofstede model. Indeed, Hofstede is one of the first people we invited to contribute to the project. I received a very gracious email from him wishing us luck on the book.

Fortunately, Camille has been a very active member of the American Marketing Association's Global Marketing Special Interest Group and, thus, she has a very broad network of colleagues and co-authors that she has collaborated with through the years. Among them are some of the most prolific global marketing scholars of the past and present. We sent the opening paragraphs above to a select list of marketing scholars and signed my (relatively unknown) and Camille's (very well-known) names. We were thrilled with the response we got that enabled us to create the distinguished list of authors in our table of contents. Several of these authors were enlisted to blindly review the chapters submitted for inclusion in this volume. I thank them for their time and their candor.

\section{ORGANIZATION OF THE BOOK}

You will note that this handbook begins with a Foreword by Jean-Claude Usunier. Dr. Usunier was among the first scholars I contacted after signing the contract with Edward Elgar Publishing. Shortly thereafter, I received a copy of his recently published volume International \& Cross-Cultural Business Research that he co-authored with Hester van Herk and Julie Anne Lee. My first instinct was that these authors had beaten us to the punch. However, upon further inspection, there is very little overlap between their book and this project. Rather, the two approaches complement one another and between them do not exhaustively cover all that can be and should be covered in a single global and cross-cultural research book.

Nonetheless, Dr. Usunier graciously declined to contribute a full chapter to this project having recently completed a major work of his own. I decided to push the matter in 2018 and preliminarily invited him to write the Foreword you might have just read. He tentatively agreed. However, it was not until 2019, when I shared with him the table of contents and accompanying abstracts we had received over the past year, that he enthusiastically jumped onboard to write the Foreword. I take his enthusiasm as excitement about the scope of this project and the expertise of the contributing authors.

\section{Part I: Cross-Cultural Marketing Themes and Theories}

Part I provides an overview of the various models that have been used to study cross-cultural differences and similarities across markets. In addition to the task-orientation versus relationship-oriented classification model she developed with 
Michael Copeland, Camille Schuster reviews the work of Edward T. Hall, Geert Hofstede, Jean-Claude Usunier, Fons Trompenaars, and John Graham. The latter two authors have each contributed some of their most recent work and newest insights in the following chapters.

Balancing globalization versus glocalization has been a popular topic for global market researchers. In his chapter, Svend Hollensen sets out to improve the understanding of glocalization by using a case methodology approach. The main goal of this exploratory research is to provide an understanding of the glocalization drivers for two companies (Henkel and Electrolux) and understand how they have each been able to balance the demands of globalization (centralization) and localization (decentralization) within their product categories and global organizational set-ups. This chapter provides an excellent example of how to conduct and effectively present comparative case studies.

In their chapter, Saeed Samiee and Brian Chabowski provide a thorough review of the intellectual basis and future directions of country image literature, one of the most researched topics over the past 50 years of global marketing research. The authors identified 45 of the most cited country image studies and, through a unique process of spatial configuration, unfold six groups of influential works with a shared knowledge base. In so doing, the authors identify promising areas of future research.

\section{Part II: Methodological Challenges of Cross-Cultural Marketing Research}

This part frames the challenges of the process of conducting marketing research. The section begins with a cautionary chapter by Michael Czinkota and Camille Schuster that points out the potential pitfalls faced by managers who fail to appreciate the complexity of researching international markets, diverse consumers within national markets, and data-collection techniques.

V. Kumar continues this theme in a chapter that focuses on establishing data equivalence. Specifically, this chapter (a) provides an overview of the equivalence issues in a cross-national study and discusses the four types of equivalence - construct, measurement, sampling, and analysis; (b) identifies how the accuracy of scales can be ensured to generate valid cross-cultural results; and (c) presents important cross-cultural issues that could arise during scale development and questionnaire design.

\section{Part III: Applied Cross-Cultural Marketing Research}

Part III focuses on applications of cross-cultural marketing research. It includes both international and intra-national studies. Siva Balasubramanian, Deepa Pillai, Giacomo Gistri, Nadia Sabour, and Hemant Patwardhan contrast US and Finnish consumer attitudes toward product placements in film, song, and television. Annie Peng Cui, Christopher Nelson, and Alexis Yim frame a set of research propositions related to how cultural differences affect motivations to consume luxury goods. Kelly Hewett and Helena Allman examine intra-national culture differences in 
thinking styles and the importance of technological product attributes for brand perceptions. Phil Harris and Ozlem Ozdemir provide a chapter that focuses on the role of family-owned businesses in the marketplace and provide a taxonomy for generational evolution and directions for future research.

Balasubramanian and his co-authors provide a textbook case of how to thoroughly conduct a structural equations modelling study using data from multiple countries. They carefully use all the proper approaches to ensure data comparability that are presented in Part IV of this book. Furthermore, their chapter moves beyond the heretofore US-centric product placement literature by using a scale originally written in Finnish and translated to English. Interestingly, while the model fits well for both the US and Finnish samples, the fit is slightly better for the Finnish sample.

Focusing on the luxury sector that has experienced high growth in recent years, particularly in non-western markets, Annie Peng Cui and her colleagues put forth a set of research propositions to examine how cultural differences affect motivations to consume luxury goods. While consumers in different cultures may choose to consume the same luxury brands, their reasons for doing so may vary. The propositions are framed through the lens of independent versus interdependent self-construal, Hofstede's six cultural dimensions, and the Confucian concept of face. These well-conceived propositions provide fertile direction for scholars interested in empirically testing them.

Self-construal also plays an important role in the subsequent chapter by Kelly Hewett and Helena Allman. In particular, based on evidence of differences in their preference for new or particularly innovative or technology-oriented products and features, the authors assess whether and how consumers with analytic versus holistic cognitive thinking styles, associated with independent versus interdependent self-construal, differentially value information regarding technology-related features of new products in their brand image evaluations. They investigate patterns of thinking styles within and across national boundaries in order to provide evidence for managers in making important segmentation and targeting decisions when introducing new products.

In their chapter, Fatima Wang and Pervez Ghauri explore the importance of partnerships in international marketing. They do this in the context of retailing. Their work illustrates the benefits local retailers can gain through partnering with global retail players. Drawing on Matthews' newcomers theory and analyzing case histories, they argue that local retailers seek multinational partnerships to build up their resource base and develop other business operations. Moreover, such development engenders growth and makes internationalization possible for the local retailer. This is particularly important in an era in which local businesses continue to feel threatened by globalization.

Maxwell and Tiffany Winchester argue that being big is an advantage in global markets. While many might assume that global companies are larger than local ones, the Winchesters point out that this is not always the case and that large, well-entrenched local companies often enjoy a competitive advantage. Their chapter frames the discussion of bigness using two principles that the authors define as the 
Double Jeopardy Law and the Duplication of Purchase Law. The authors provide empirical evidence from previous studies that shows that both laws support the advantages of large players regardless of whether the large player is multinational or local. Furthermore, the empirical evidence supports that these laws are robust across country settings as well as industry sectors and thus may be truisms.

In their chapter, Phil Harris and Ozlem Ozdemir remind us that some of the largest global companies are, in fact, closely held family businesses. However, the extent to which the management of the company is as closely held as the ownership of the shares often evolves over time as the business is passed down from generation to generation. Recognizing that research specifically focused on family-owned international and global businesses is scant, the authors investigate the general implications of succession planning, as well as the specific implications of what happens when the heir apparent is a daughter rather than a son.

Eric Rhodes addresses the potential for introducing testing environment biases arising from applying Western-based standardized testing norms when measuring individualism and collectivism (idiocentrism and allocentrism) in non-Western cultural contexts. He does this by using a smartphone-based application that allows respondents to complete the survey instrument from any location at any time. This is an example of how technology may revolutionize the way scholars conduct cross-cultural research as described in Part IV.

\section{Part IV: New Paradigms and Future Research}

This part opens with a chapter by Fons Trompenaars and Peter Woolliams. Their chapter presents a new approach to understanding corporations by investigating how they solve problems framed as a series of dilemmas. These dilemmas include: universalism versus particularism; individualism versus communitarianism; specificity versus diffusion; neutral versus affective orientation: achievement versus ascription; and internal versus external control. The authors describe how they use these six dilemmas as lenses through which they can help companies solve their problems.

This is followed by John Graham's chapter on advances in theory and methods for research in international business negotiations. After reviewing the extant literature, including his own extensive work, Graham also describes the methods, processes, and outcomes of his team's laboratory research in 22 countries. He goes further by introducing and discussing two advances in measurement - linguistic measurement and facial recognition. Beyond that, his chapter closes with a discussion of a third theory of negotiation that emphasizes relationships over agreements and the search for mutual opportunities over problem solving that should prove useful for future research studies.

Based upon their vast experience, Jagdish Sheth and Atul Parvatiyar identify several driving forces beyond the trends that will provide opportunities and challenges for twenty-first-century marketing researchers. These include: unbranded competition, faith-based consumption, diaspora marketing, social media marketing research, marketing to low-income consumers, sustainable marketing, and genet- 
ics, climate, and consumption. Beyond identifying these critical areas of inquiry, the chapter also addresses how technology will revolutionize the ways in which cross-cultural marketing research will be conducted.

The final chapter synthesizes the ideas generated throughout the book. It is designed to summarize the various themes, methodologies, issues, and industries presented throughout the handbook in one place. Glen Brodowsky extracts a list of promising research areas - and specific research questions - that experienced as well as up-and-coming global marketing researchers might wish to tackle as we move our discipline forward into the future.

\section{REFERENCES}

Levitt, T. (1983), "The globalization of markets", Harvard Business Review, May/June, 39-49. Usunier, J., van Herk, H. \& Lee, J. (2017), International and cross-cultural business research, 55 City Road, London: SAGE Publications Ltd. 